\title{
Residual Disease Burden in Patients With Axial Spondyloarthritis and Psoriatic Arthritis Despite Low Disease Activity States in a Multiethnic Asian Population
}

\author{
Venice Liu ${ }^{1}$, Warren Fong ${ }^{2}$ (D) Yu Heng Kwan ${ }^{3}$ (D) and Ying Ying Leung ${ }^{2}$ (D)
}

\begin{abstract}
Objectives. To evaluate the burden of residual disease in patients with axial spondyloarthritis (axSpA) or psoriatic arthritis (PsA) who achieved low disease activity (LDA) status.

Methods. We used baseline data from a clinic registry of SpA in a tertiary hospital in Singapore. For axSpA, LDA was defined as Ankylosing Spondylitis (AS) Disease Activity Score based on erythrocyte sedimentation rate $($ ASDAS-ESR) $<2.1$ or Bath AS Disease Activity Index (BASDAI) $<3 / 10$. For PsA, LDA was defined by achieving $5 / 7$ cutoffs in the minimal disease activity (MDA) or Clinical Disease Activity Index for Psoriatic Arthritis (cDAPSA) $\leq 13$.

Results. In 262 cases of axSpA (21\% women; mean \pm standard deviation (SD) age $42 \pm 14 \mathrm{yrs}$ ), $33 \%$ and $43 \%$ of patients achieved ASDAS-ESR and BASDAI LDA states, respectively, while in 142 cases of PsA ( $49 \%$ women, mean age $51 \pm$ SD 14 yrs), 35\% and 63\% achieved MDA and cDAPSA LDA, respectively. Both axSpA and PsA patients with LDA had pain scores ranging from 14.0 to 21.4/100 and fatigue scores ranging from 3.1 to $3.6 / 10$. Substantial burden in physical disability and mental well-being were observed, with low physical and mental component summary scores on the 36-item Short Form Health Survey. AxSpa patients in BASDAI LDA had higher ESR and lower disability than those in ASDAS-ESR LDA. cDAPSA classified nearly twice as many PsA patients into LDA than MDA. Compared to PsA patients in MDA LDA, those in cDAPSA LDA had higher active joint counts, dactylitis, enthesitis, pain scores, and patient global assessment.

Conclusion. Despite being in LDA, patients with axSpA and PsA experienced substantial residual burden in pain, poorer physical function, and mental well-being.
\end{abstract}

Key Indexing Terms: psoriatic arthritis, residual disease, spondyloarthritis

Spondyloarthritis $(\mathrm{SpA})$-related diseases, including axial $\mathrm{SpA}$ (axSpA) and psoriatic arthritis (PsA), are chronic systemic diseases that can cause pain, irreversible disabilities, and reduced health-related quality of life (HRQOL). To improve management of these diseases, a treat-to-target (T2T) strategy has been shown to improve clinical outcomes for patients with inflammatory arthritis ${ }^{1,2}$. Although there is consensus that clinical remission (REM) or low disease activity (LDA) states are the

YYL was supported by the National Medical Research Council, Singapore (NMRC/CSAINV/0022/2017). The funding sources had no role in the study design, data collection, analysis, interpretation of data, manuscript writing, or decision to submit.

${ }^{I} V$. Liu, BA, Singapore General Hospital, Department of Rheumatology and Immunology; ${ }^{2}$ W. Fong, MBBS, Y.Y. Leung, MB ChB, MD, Singapore General Hospital, Department of Rheumatology and Immunology, and Duke-NUS Medical School; ${ }^{3}$ Y.H. Kwan, BSc, MD, PhD, Duke-NUS Medical School, Singapore, Singapore.

All authors declare no conflicts of interest.

Address correspondence to Dr. Y.Y. Leung, Department of Rheumatology and Immunology, Singapore General Hospital, The Academia, Level 4, 20 College Road, Singapore 169856, Singapore.Email:katyccc@hotmail.com.

Full Release Article. For details see Reprints and Permissions at jrheum.org.

Accepted for publication October 19, 2020. treatment goals in the T2T strategy for the management of SpA $\mathrm{A}^{3}$. No single disease activity assessment tool was specified to identify the treatment target in both SpA and PsA ${ }^{4,5}$. Three composite scores have been recommended as possible treatment targets for SpA: the minimal disease activity (MDA) and Disease Activity Index for Psoriatic Arthritis (DAPSA) for assessing PsA; and the Ankylosing Spondylitis (AS) Disease Activity Score (ASDAS) for axSpA ${ }^{3}$.

Despite achieving the proposed clinical REM or LDA states, patients with SpA may suffer from considerable residual disease burden $^{6,7,8}$. The gap in knowledge about residual disease may have an effect on disease progression, patients' functional status, and HRQOL; an improved understanding of residual disease may help to better define the treatment goal from patients' perspectives, as well as improve both the effectiveness of treatment plans and healthcare in general.

Studies on disease burden were conducted mainly in Western populations and to our knowledge, no data exist in the Asian context. Data from several studies in PsA have shown that ethnicity has an effect on prevalence, clinical manifestations, and disease activity ${ }^{9,10}$. Pain perception and its reporting have also been shown to differ in different ethnic groups ${ }^{11}$. To incorporate patients' perspectives on treatment goals in the shared decision-making process, further understanding of disease 
burden in their perspectives is necessary. Therefore, we aimed to evaluate the residual disease burden in patients with axSpA or PsA who have achieved LDA in an Asian population in Singapore.

\section{MATERIALS AND METHODS}

Study design. We used the cross-sectional baseline data of the PREcision medicine in SPondyloarthritis for better Outcomes aND Disease remission registry ${ }^{10,12,13}$ from a tertiary rheumatology center in Singapore General Hospital from 2012 to 2018.

Participants. This registry recruited all patients who attended the designated SpA and PsA clinics. Patients were followed up in either clinic without overlapping. We included axSpA patients fulfilling the 2009 Assessment of SpondyloArthritis international Society classification criteria ${ }^{14}$ and PsA patients fulfilling the Classification Criteria for Psoriatic Arthritis criteria for PsA ${ }^{15}$. This study was approved by the SingHealth Centralized Institutional Review Board (CIRB Ref 2012/498/E) and written informed consent was obtained from all patients prior to participation.

Data collection. We collected demographic characteristics including age, ethnicity, highest level of education, and disease duration. Body weight and height of patients were measured in the clinics. Patients were assessed by the attending rheumatologists for $66 / 68$ swollen (SJC) and tender joint counts (TJC). Among patients with PsA, dactylitis was assessed by counting the number of digits that were swollen or tender $(0-20)$, enthesitis by using the 6-point Leeds Enthesitis Index ${ }^{16}$, and skin condition by the Psoriasis Area and Severity Index. Physician global assessment of disease activity was collected on a $0-10$ numeric rating scale (NRS; $10=$ worse disease activity).

Patient-reported outcomes included the validated Bath Ankylosing Spondylitis Disease Activity Index (BASDAI), pain score, patient global assessment (PtGA), Health Assessment Questionnaire-Disability Index (HAQ-DI), and the 36-item Short Form Health Survey (SF-36), all of which have been validated in the Asian context for patients with $\mathrm{SpA}^{17,18,19,20,21}$. The BASDAI consisted of 5 domains including fatigue, back pain, peripheral joint pain, enthesitis pain, and morning stiffness (severity and duration), collected on a $0-10 \mathrm{NRS}$, with 10 indicating worse severity; the mean of the 5 domains was scored. Both PtGA and pain in the past week were assessed using a $100-\mathrm{mm}$ visual analog scale, with 100 indicating worse assessment. The HAQ-DI ranged from 0 to 3, with 3 indicating worse disability.

Disease activity assessment and LDA status. Disease activity in axSpA was assessed by ASDAS and BASDAI. ASDAS with erythrocyte sedimentation rate (ESR) was used because $\mathrm{C}$-reactive protein (CRP) was not routinely collected at the beginning of the registry. We defined LDA for axSpA in the current study as having ASDAS-ESR ${ }^{22}<2.1$ or BASDAI score $<3 / 10$. These LDA criteria have been used in several studies on the treatment of $A S^{23,24,25}$.

Two composite scores were used to assess disease activities in PsA: (1) minimal disease activity (MDA), which evaluates 7 domains including enthesitis, TJC, SJC, psoriasis, pain, PtGA, and HAQ-DI ${ }^{26}$; and (2) Clinical DAPSA (cDAPSA) ${ }^{27,28}$, which assesses SJC, TJC, PtGA, and pain. Patients were classified as being in an LDA state if they met $5 / 7$ cutoffs in MDA or if cDAPSA score of $\leq 13$ was achieved ${ }^{28}$. cDAPSA was used instead of the original DAPSA due to incomplete data collection for CRP at the beginning of the registry.

Statistical analysis. Descriptive statistics were reported as mean and SD. We compared characteristics for patients who achieved/did not achieve LDA in axSpA and PsA separately using $t$-test or chi-square test, as appropriate. For both axSpA and PsA patients who achieved LDA, we described the proportion of patients with residual disease in each categorical criterion of the composite assessment, and the proportion having HRQOL scores < 50th percentile (normal) and $<10$ th percentile (representing severe HRQOL impairment ${ }^{29}$ of the general population ${ }^{30}$. Statistical hypothesis tests were 2 -tailed and $P$ values < 0.05 were considered statistically significant. The data were analyzed using IBM SPSS Statistics v25 (IBM Corp.).

\section{RESULTS}

A total of 262 patients with axSpA (21\% women; mean \pm SD age $42 \pm 14$ yrs) and 142 patients with PsA (49\% women; mean $\pm \mathrm{SD}$ age $51 \pm 14 \mathrm{yrs}$ ) were analyzed in this study (Table 1 ). As previously reported, patients with axSpA had long disease duration, with $82 \%$ fulfilling radiographic sacroiliitis criteria ${ }^{13}$. Compared to patients with PsA, patients with axSpA were younger and more likely to be men. The ethnic distribution of axSpA was comparable to the national distribution in Singapore (Chinese $74.1 \%$, Malay $13.4 \%$, Indian $9.2 \%$, and other $3.3 \%)^{31}$; whereas among PsA, Indians were overrepresented, as previously described ${ }^{10}$. Disease duration in patients with axSpA was significantly longer than that of PsA patients (mean \pm SD: $10.1 \pm 8.3$ vs $4.9 \pm 6.0$ mos). Compared to patients with axSpA, patients with PsA had higher BMI, higher active joint counts, and higher disability measured by HAQ-DI. However, there were no statistically significant differences in pain, BASDAI, and PtGA scores between axSpA and PsA patients. Out of 262 patients with axSpA, only 167 patients were given SF-36 to complete in the clinic; this was related to nondifferential missing during days when the clinic was not supported by research assistants. All patients with PsA completed SF-36. There were no statistically significant differences in all SF-36 domains when comparing patients with axSpA and PsA. Patients from both study cohorts had poorer HRQOL compared to the general population, as indicated by lower norm-based SF-36 physical (PCS) and mental component summary scores (MCS) ranging from 40.5 to 43.9.

There were 87 (33\%) and $112(43 \%)$ patients with axSpA who achieved LDA according to ASDAS-ESR and BASDAI, respectively. There were $50(35 \%)$ and 90 (63\%) patients with PsA who achieved LDA according to the MDA and cDAPSA, respectively. Patients with AxSpA who achieved LDA had lower disease activity measures, lower disease impact, and better HRQOL compared with those not achieving LDA (Supplementary Table 1, available with the online version of this article), and similarly for PsA patients (Supplementary Table 2).

The residual disease burden in patients with axSpA and PsA who achieved LDA by different criteria are summarized in Table 2. Patients with axSpA who achieved LDA by ASDAS-ESR and by BASDAI had low active joint counts. However, both groups of axSpA LDA patients were still experiencing high residual pain (20.8 to $21.4 / 100)$, fatigue (3.2 to $3.6 / 10)$, and reported moderate PtGA (22.7 to 24.0/100) scores. Further, patients with axSpA in both ASDAS-ESR and BASDAI LDA reported burden in physical disability and mental well-being, with lower mean norm-based PCS and MCS compared to that of the general population mean (Table 2).

Similarly, patients with PsA in LDA defined by either the MDA or CDAPSA criteria were having high residual burden in pain (14.0 to 20.8/100), fatigue (3.1 to 3.4/10), moderate PtGA (17.8 to 23.5/100), and poor HRQOL (Table 2). Patients classified as LDA using MDA had a mean \pm SD TJC of $0.5 \pm 0.7$ and SJC of $0.5 \pm 1.0$, whereas patients classified as LDA by cDAPSA had a higher mean \pm SD TJC of $1.0 \pm 1.4$ and SJC of $0.9 \pm 1.3$ Apart from having residual active joint counts, patients with PsA in LDA by either MDA or cDAPSA also reported lower 
Table 1. Demographic and clinical characteristics of study patients with axSpA and PsA.

\begin{tabular}{|c|c|c|c|}
\hline & $\mathrm{axSpA}, \mathrm{n}=262$ & PsA, $n=142$ & $P$ \\
\hline Age, yrs & $41.7(13.7)$ & $51.1(13.8)$ & $<0.01$ \\
\hline Female, n (\%) & $55(21.0)$ & $69(48.6)$ & $<0.01$ \\
\hline Ethnicity, n (\%) & & & $<0.01$ \\
\hline Chinese & $216(82.4)$ & $94(66.2)$ & \\
\hline Indian & $21(8.0)$ & $34(23.9)$ & \\
\hline Malay & $9(3.4)$ & $11(7.7)$ & \\
\hline Other & $16(6.2)$ & $3(2.2)$ & \\
\hline Disease duration, yrs & $10.1(8.3)$ & $4.9(6.0)$ & $<0.01$ \\
\hline $\mathrm{BMI}, \mathrm{kg} / \mathrm{m}^{2}$ & $24.6(6.1)$ & $26.3(5.2)$ & $<0.01$ \\
\hline TJC & $0.3(1.8)$ & $3.2(4.0)$ & $<0.01$ \\
\hline SJC & $0.2(1.1)$ & $2.2(3.0)$ & $<0.01$ \\
\hline VAS pain $(0-100)$ & $36.5(22.9)$ & $33.5(25.6)$ & 0.08 \\
\hline ASDAS-ESR & $2.5(1.1)$ & - & - \\
\hline $\operatorname{BASDAI}(0-10)$ & $3.6(1.9)$ & $3.7(2.2)$ & 0.85 \\
\hline PtGA $(0-100)$ & $38.7(22.9)$ & $34.4(24.2)$ & 0.05 \\
\hline PGA $(0-10)$ & $2.6(1.7)$ & $3.2(2.1)$ & 0.02 \\
\hline Dactylitis $(0-20)$ & - & $0.8(1.5)$ & - \\
\hline LEI $(0-6)$ & - & $0.4(0.8)$ & - \\
\hline cDAPSA & - & $12.2(9.5)$ & - \\
\hline PASI (0-72) & - & $3.6(6.2)$ & - \\
\hline HAQ-DI (0-3) & $0.3(0.4)$ & $0.4(0.6)$ & $<0.01$ \\
\hline \multicolumn{4}{|l|}{ SF-36 subscales } \\
\hline$P F(0-100)$ & $73.7(22.3)$ & $66.6(27.1)$ & 0.04 \\
\hline $\mathrm{RP}(0-100)$ & $73.5(24.7)$ & $71.2(27.8)$ & 0.72 \\
\hline $\mathrm{BP}(0-100)$ & $57.0(21.4)$ & $58.3(22.5)$ & 0.53 \\
\hline $\mathrm{GH}(0-100)$ & $53.7(20.6)$ & $53.7(19.4)$ & 0.95 \\
\hline $\operatorname{VT}(0-100)$ & $57.4(18.2)$ & $53.6(20.1)$ & 0.17 \\
\hline $\mathrm{SF}(0-100)$ & $75.8(22.1)$ & $75.3(24.6)$ & 0.91 \\
\hline $\operatorname{RE}(0-100)$ & $79.4(23.0)$ & $76.3(28.5)$ & 0.71 \\
\hline $\mathrm{MH}(0-100)$ & $69.9(19.1)$ & $67.6(20.5)$ & 0.42 \\
\hline PCS & $41.8(12.0)$ & $40.5(13.4)$ & 0.64 \\
\hline MCS & $43.9(11.3)$ & $42.6(11.9)$ & 0.37 \\
\hline
\end{tabular}

Values expressed in mean (SD) unless specified otherwise. ASDAS-ESR: Ankylosing Spondylitis Disease Activity Score based on erythrocyte sedimentation rate; axSpA: axial spondyloarthritis; BASDAI: Bath Ankylosing Spondylitis Disease Activity Index; BP: bodily pain; cDAPSA: Clinical Disease Activity in Psoriatic Arthritis; GH: general health; HAQ-DI: Health Assessment Questionnaire-Disability Index; LEI: Leeds Enthesitis Index; MCS: norm-based mental component summary (mean 50, SD 10); MH: mental health; PASI: Psoriasis Area Severity Index; PCS: norm-based physical component summary (mean 50, SD 10); PF: physical function; PGA: physician global assessment; PsA: psoriatic arthritis; PtGA: patient global assessment; RE: role emotional; RP: role physical; SF: social functioning; SF-36: 36-item Short Form Health Survey; SJC: swollen joint count; TJC: tender joint count; VAS: visual analog scale; VT: vitality.

scores of norm-based PCS and MCS than the general population (Table 2). Compared to MDA criteria, cDAPSA classified almost double the number of PsA patients as having LDA ( 90 vs 50 patients); these patients had higher dactylitis and enthesitis counts, pain score, fatigue, PtGA, and disability by HAQ-DI.

Table 3 and Table 4 summarize the proportion of patients with LDA having residual disease by categorical criteria in the composite assessment, as well as those having SF-36 domains lower than the 50th and 10th percentiles of the general population. Among the axSpA LDA patients, more than half of them had residual pain and fatigue symptoms, and over $40 \%$ had PtGA > 20/100. Eight percent and 34.7\% in patients with ASDAS-ESR LDA and BASDAI LDA, respectively, had elevated ESR. There were $33-72 \%$ of patients with axSpA LDA who had worse HRQOL domains than the 50th percentile of the general population, while $10-34 \%$ of them had HRQOL scores below the 10th percentile of general population. Almost half and $13-14 \%$ of the patients with ASDAS-ESR LDA and BASDAI LDA, respectively, had norm-based PCS below the 50th and 10th percentile of the general population, whereas two-thirds and more than one-quarter of them had poor psychological health (by norm-based MCS) below the 50th and 10th percentile of the general population, respectively. As for patients with PsA in LDA by MDA and cDAPSA criteria, $6-10 \%$ and $20-24 \%$, respectively, had residual active joints. There were $38 \%$ and $58 \%$ of patients with PsA in LDA by MDA and cDAPSA who had residual pain, respectively, while close to two-thirds had residual fatigue by either criterion. Over 
Table 2. Residual disease burden in axSpA and PsA patients who achieved LDA.

\begin{tabular}{|c|c|c|c|c|}
\hline & \multicolumn{2}{|c|}{ axSpA } & \multicolumn{2}{|c|}{ PsA } \\
\hline & $\begin{array}{l}\text { LDA by ASDAS-ESR } \\
\qquad 2.1\end{array}$ & $\begin{array}{c}\text { LDA by BASDAI } \\
<3 / 10\end{array}$ & LDA by MDA & LDA by cDAPSA \\
\hline Age, yrs & $40.6(13.7)$ & $32.8(12.6)$ & $53.8(13.4)$ & $52.5(13.2)$ \\
\hline Women, n (\%) & $11(12.6)$ & $20(17.9)$ & $28(56.0)$ & $45(50.0)$ \\
\hline \multicolumn{5}{|l|}{ Ethnic group, n (\%) } \\
\hline Disease duration, yrs & $8.8(6.4)$ & $9.6(7.9)$ & $5.5(5.9)$ & $5.2(6.0)$ \\
\hline $\mathrm{BMI}, \mathrm{kg} / \mathrm{m}^{2}$ & $24.7(6.8)$ & $24.7(6.4)$ & $25.7(5.0)$ & $26.1(4.7)$ \\
\hline $\operatorname{TJC}(0-68)$ & $0.1(0.3)$ & $0.1(0.3)$ & $0.5(0.7)$ & $1.0(1.4)$ \\
\hline $\operatorname{SJC}(0-66)$ & $0.0(0.2)$ & $0.0(0.2)$ & $0.5(1.0)$ & $0.9(1.3)$ \\
\hline VAS pain $(0-100)$ & $20.8(16.6)$ & $21.4(17.6)$ & $14.0(13.8)$ & $20.8(16.7)$ \\
\hline PtGA $(0-100)$ & $22.7(16.9)$ & $24.0(19.5)$ & $17.8(14.8)$ & $23.5(17.6)$ \\
\hline PGA $(0-10)$ & $1.9(1.2)$ & $1.6(1.0)$ & $1.7(1.2)$ & $2.2(1.5)$ \\
\hline Dactylitis $(0-20)$ & - & - & $0.2(0.5)$ & $0.5(0.9)$ \\
\hline $\operatorname{LEI}(0-6)$ & - & - & $0.1(0.3)$ & $0.2(0.5)$ \\
\hline PASI $(0-72)$ & - & - & $1.9(3.7)$ & $2.4(3.8)$ \\
\hline $\mathrm{ESR}, \mathrm{mm} / \mathrm{h}$ & $8.1(8.2)$ & $21.1(23.2)$ & $16.3(13.9)$ & $18.6(15.9)$ \\
\hline HAQ-DI $(0-3)$ & $0.1(0.3)$ & $0.1(0.2)$ & $0.1(0.2)$ & $0.2(0.4)$ \\
\hline \multicolumn{5}{|l|}{ SF-36 } \\
\hline PF $(0-100)$ & $84.1(16.4)$ & $84.5(15.7)$ & $77.4(24.4)$ & $74.5(24.3)$ \\
\hline $\mathrm{RP}(0-100)$ & $85.3(17.9)$ & $84.4(18.8)$ & $82.0(26.2)$ & $78.5(25.3)$ \\
\hline $\mathrm{BP}(0-100)$ & $70.0(16.9)$ & $70.5(15.6)$ & $72.0(19.0)$ & $67.7(18.5)$ \\
\hline $\mathrm{GH}(0-100)$ & $58.1(20.3)$ & $58.7(20.4)$ & $63.4(16.0)$ & $58.8(17.4)$ \\
\hline
\end{tabular}

Values expressed in mean (SD) unless specified otherwise. ASDAS-ESR: Ankylosing Spondylitis Disease Activity Score based on erythrocyte sedimentation rate; axSpA: axial spondyloarthritis; BASDAI: Bath Ankylosing Spondylitis Disease Activity Index; BP: bodily pain; cDAPSA: Clinical Disease Activity in Psoriatic Arthritis; ESR: erythrocyte sedimentation rate; GH: general health; HAQ-DI: Health Assessment Questionnaire-Disability Index; LDA: low disease activity; LEI: Leeds Enthesitis Index; MCS: norm-based mental component summary (mean 50, SD 10); MDA: minimal disease activity; MH: mental health; PASI: Psoriasis Area Severity Index; PCS: norm-based physical component summary (mean 50, SD 10); PF: physical function; PGA: physician global assessment; PsA: psoriatic arthritis; PtGA: patient global assessment; RE: role emotional; RP: role physical; SF: social functioning; SF-36: 36-item Short Form Health Survey; SJC: swollen joint count; TJC: tender joint count; VAS: visual analog scale; VT: vitality.

one-third and one-half, respectively, had residual skin disease, and approximately one-third by both criteria had elevated ESR. SF-36 domain scores were below norm of the general population in $38-67 \%$ and $53--6 \%$ of patients with PsA classified as LDA by MDA or cDAPSA criteria, respectively. As for severe HRQOL impairment with SF-36 domain scores below the 10th percentile of the general population, it was reported in $12-28 \%$ and $19-27 \%$ of patients with PsA classified as LDA by MDA or cDAPSA criteria, respectively (Table 4). Patients classified as LDA by cDAPSA had higher residual disease burden than those classified by MDA, including active joint counts, dactylitis, enthesitis, pain, PtGA, and impact on HRQOL.

\section{DISCUSSION}

In this study, we evaluated the residual disease burden in a cohort of patients with axSpA and PsA in a multiethnic Asian population. Patients with either disease spectrum who achieved LDA states still reported substantial burden in disease activity, pain, and fatigue, and across all aspects of HRQOL. Residual disease burden in SpA has been reported in Western studies previously ${ }^{6,732,33}$. To our knowledge, this is the first study that reports residual disease burden among patients with axSpA. It is also the first to report residual disease burden in SpA patients among Asian patients, described separately for axSpA and PsA.

The high burden of residual disease among PsA patients with LDA is generally consistent with that of Western literature. 
Table 3. Proportion of patients in LDA having residual disease in different categories.

\begin{tabular}{lcccc}
\hline & \multicolumn{2}{c}{ axSpA LDA } & \multicolumn{2}{c}{ PsA LDA } \\
& $\begin{array}{c}\text { by ASDAS-ESR } \\
<2.1, \mathrm{n}=87 \\
(\%)\end{array}$ & $\begin{array}{c}</ 10, \mathrm{n}=112 \\
(\%)\end{array}$ & $\begin{array}{c}\mathrm{n}=50 \\
(\%)\end{array}$ & $\begin{array}{c}\mathrm{n}=90 \\
(\%)\end{array}$ \\
\hline $\mathrm{TJC}>1$ & 2.3 & 1.8 & 10.0 & 24.4 \\
SJC $>1$ & 1.1 & 0.9 & 6.0 & 20.0 \\
VAS pain $>15 / 100$ & 52.9 & 52.7 & 38.0 & 57.8 \\
BASDAI fatigue $>2 / 10$ & 62.1 & 58.9 & 60.0 & 64.6 \\
BASDAI back pain $>1 / 10$ & 67.8 & 65.2 & 46.7 & 59.8 \\
PtGA $>20 / 100$ & 41.4 & 41.1 & 32.0 & 51.1 \\
Dactylitis $>1$ & - & - & 3.4 & 10.0 \\
LEI $>1$ & - & - & 0.0 & 3.3 \\
PASI $>1$ & - & - & 34.0 & 52.2 \\
Elevated ESR $(>20 \mathrm{~mm} / \mathrm{h})$ & 8.0 & 34.7 & 28.0 & 35.8 \\
HAQ-DI $>0.5$ & 8.0 & 4.4 & 4.0 & 14.4 \\
\hline
\end{tabular}

ASDAS-ESR: Ankylosing Spondylitis Disease Activity Score based on erythrocyte sedimentation rate; axSpA: axial spondyloarthritis; BASDAI: Bath Ankylosing Spondylitis Disease Activity Index; cDAPSA: Clinical Disease Activity in Psoriatic Arthritis; ESR: erythrocyte sedimentation rate; HAQ-DI: Health Assessment Questionnaire-Disability Index; LDA: low disease activity; LEI: Leeds Enthesitis Index; MDA: minimal disease activity; PASI: Psoriasis Area Severity Index; PsA: psoriatic arthritis; PtGA: patient global assessment; SJC: swollen joint count; TJC: tender joint count; VAS: visual analog scale.

Table 4. Proportion of patients in LDA having residual disease in HRQOL domains.

\begin{tabular}{|c|c|c|c|c|}
\hline & \multicolumn{2}{|c|}{ axSpA LDA } & \multicolumn{2}{|c|}{ PsA LDA } \\
\hline & $\begin{array}{c}\text { by ASDAS-ESR } \\
<2.1, \mathrm{n}=87 \\
(\%)\end{array}$ & $\begin{array}{c}\text { by BASDAI } \\
<3 / 10, \mathrm{n}=112 \\
(\%)\end{array}$ & $\begin{array}{c}\text { by MDA, } \\
\mathrm{n}=50 \\
(\%)\end{array}$ & $\begin{array}{c}\text { by cDAPSA, } \\
\mathrm{n}=90 \\
(\%)\end{array}$ \\
\hline \multicolumn{5}{|c|}{ SF-36 $<50$ th percentile of general population } \\
\hline PF & 34.0 & 32.8 & 44.9 & 52.8 \\
\hline $\mathrm{RP}$ & 48.0 & 50.7 & 42.0 & 54.4 \\
\hline $\mathrm{BP}$ & 72.0 & 70.1 & 66.0 & 75.6 \\
\hline $\mathrm{GH}$ & 70.0 & 64.2 & 62.0 & 72.2 \\
\hline VT & 60.0 & 52.2 & 66.0 & 67.8 \\
\hline SF & 56.0 & 52.2 & 48.0 & 55.6 \\
\hline $\mathrm{RE}$ & 44.0 & 38.8 & 38.0 & 40.0 \\
\hline $\mathrm{MH}$ & 62.0 & 53.7 & 56.0 & 57.8 \\
\hline PCS & 48.0 & 46.3 & 49.0 & 52.8 \\
\hline MCS & 64.0 & 61.2 & 67.3 & 69.7 \\
\hline \multicolumn{5}{|c|}{ SF-36 $\leq 10$ th percentile of general population } \\
\hline PF & 16.0 & 10.4 & 24.5 & 24.4 \\
\hline $\mathrm{RP}$ & 12.0 & 16.4 & 18.0 & 26.7 \\
\hline $\mathrm{BP}$ & 24.0 & 19.4 & 18.0 & 23.3 \\
\hline $\mathrm{GH}$ & 34.0 & 23.9 & 16.0 & 25.6 \\
\hline VT & 14.0 & 16.4 & 22.0 & 23.3 \\
\hline SF & 20.0 & 22.4 & 22.0 & 23.3 \\
\hline $\mathrm{RE}$ & 18.0 & 17.9 & 16.0 & 18.9 \\
\hline $\mathrm{MH}$ & 24.0 & 25.4 & 28.0 & 27.8 \\
\hline PCS & 14.0 & 13.4 & 12.2 & 20.0 \\
\hline MCS & 26.0 & 25.4 & 20.4 & 22.5 \\
\hline
\end{tabular}

ASDAS-ESR: Ankylosing Spondylitis Disease Activity Score based on erythrocyte sedimentation rate; axSpA: axial spondyloarthritis; BASDAI: Bath Ankylosing Spondylitis Disease Activity Index; BP: bodily pain; cDAPSA: Clinical Disease Activity in Psoriatic Arthritis; GH: general health; HRQOL: health-related quality of life; LDA: low disease activity; MCS: norm-based mental component summary (mean 50, SD 10); MDA: minimal disease activity; MH: mental health; PCS: norm-based physical component summary (mean 50, SD 10); PF: physical function; PsA: psoriatic arthritis; RE: role emotional; RP: role physical; SF: social functioning; SF-36: 36-item Short Form Health Survey; VT: vitality. 
In an observational study from 2 centers in the Netherlands, more than half of the patients with PsA who were in MDA had residual disease in their joints, and $40 \%$ had residual disease in their $\operatorname{skin}^{34}$. Data from an Italian cohort reported that half of the subjects had active disease activity in skin ${ }^{35}$. Residual skin disease burden was seen in 34-52\% of our patients with PsA LDA. Apart from residual burden in skin and joints, we demonstrated high burden in pain, fatigue, and impaired HRQOL in patients in LDA for both spectra of SpA. This corroborates the results from a prospective cohort of newly diagnosed patents with $\mathrm{PsA}^{36}$ in which up to a third of patients who achieved LDA at 1-year follow-up had pain score $>1.5 / 10$ and PGA $>2.0 / 10$. Similarly, a study in Turkey reported residual disease in joint count, enthesitis, and dacylitis ${ }^{6}$. In addition, the Turkish study described $22.2 \%$ and $11 \%$ of patients with PsA in MDA as having symptoms of depression and anxiety, respectively, in addition to high fatigue (median 2.0).

Our study also reported some differences from Western literature in the residual disease burden in patients with PsA. In the Italian cohort, only a minority (5\%) of patients fulfilling MDA presented a clinically significant number of $\mathrm{SJC}^{35}$, whereas the study in Turkey reported no SJC in patients who fulfilled $\mathrm{MDA}^{6}$. In contrast, $6 \%$ and $20 \%$ of our patients with PsA LDA classified by MDA or CDAPSA, respectively, had SJC $>1$. As for patients with TJC $>1$, it was observed only in $2.4 \%$ of patients with MDA in the Italian study and 33\% in the Turkish study, but seen in $10-24 \%$ of our patients classified by MDA or cDAPSA. Further, the Turkish study reported no disability in MDA patients ${ }^{6}$, whereas in our study, $4-14 \%$ of patients fulfilling MDA and CDAPSA had more than minimal residual disability (HAQ-DI > 0.5). To support the Turkish study that reported residual anxiety and depression, more than two-thirds and up to one-fifth of the patients with PsA LDA in our cohort had very poor mental health, as measured by MCS scores below the 50th and 10th percentiles, respectively, of the normal population.

Our study highlights the importance of pain, fatigue, physical disability, and mental health in assessing disease activity states. Despite clinically inactive disease being assessed by different definitions of LDA, patients with both axSpA and PsA were not entirely in good shape. Current tools that assess disease activity might not have adequately addressed the impact of disease from the patients' perspectives. The discordance in PtGA between patients and their physicians has been described previously in both conditions in the Asian context ${ }^{37,38}$. Our study has shown that pain, fatigue, and the psychological aspects of health were the key burdens of residual disease in both spectra of $\mathrm{SpA}$; these aspects are usually less recognized by physicians. The results of our present study highlight once again the importance of incorporating patients' perspectives in the shared decision-making process for the management of SpA. Of note, residual diseases recognized by physicians may not lead to a change of medication $^{34}$. To improve current instruments to determine treatment target, there is a need to identify domains that are more closely related to inflammation; this will guide a change of disease-modifying drugs as opposed to needing alternative management to address disease impact ${ }^{39}$.
We recognize differences between the groups of patients who were classified as LDA by different criteria. These differences are most notable between patients with PsA LDA classified by MDA vs cDAPSA, with MDA seemingly the more stringent criteria. First, cDAPSA classified almost double the number of patients with PsA to LDA. Second, patients with PsA in LDA by MDA had less pain, lower PtGA, and lower disability than those classified by cDAPSA. Moderate to large discrepancies between proportions of patients identified as LDA by MDA vs cDAPSA have been previously reported ${ }^{6,33,34,36,40,41}$. These discrepancies were probably driven by residual skin disease, enthesitis, and physical disability that were not assessed in cDAPSA. As for axSpA, patients classified as LDA by ASDAS-ESR and BASDAI had similar scores in most aspects, except a lower burden of residual ESR as classified by ASDAS-ESR compared with LDA as classified by BASDAI; this is expected given the ASDAS-ESR criteria. The slightly higher proportion of disability in patients classified as LDA by ASDAS-ESR was not supported by similar score distribution in HAQ-DI in both groups (Table 2).

There are some limitations in our study. With the cross-sectional study design, we were not able to study the progression of these residual symptoms and the factors causing these symptoms to persist after achieving LDA states. The study was also performed in a tertiary referral center and the findings presented might not be representative of all patients with axSpA and PsA, particularly for those with mild disease who had follow-up visits in primary health care. Finally, there were 95 patients with axSpA who did not fill out the SF-36 questionnaire due to a lack of support with research assistants in some clinic sessions, albeit the fact that the omission of these patients was nondifferential.

In conclusion, this study revealed the presence of substantial disease burden on patients with axSpA and PsA, even after achieving LDA states, regardless of the methods used for the classification of LDA. A greater understanding of residual disease burden can help to better define treatment targets that can then be incorporated into T2T strategies to further improve their effectiveness.

\section{ACKNOWLEDGMENT}

We thank all patients who participated in the study cohort.

\section{ONLINE SUPPLEMENT}

Supplementary material accompanies the online version of this article.

\section{REFERENCES}

1. Grigor C, Capell H, Stirling A, McMahon AD, Lock P, Vallance R, et al. Effect of a treatment strategy of tight control for rheumatoid arthritis (the TICORA study): a single-blind randomised controlled trial. Lancet 2004;364:263-9.

2. Coates LC, Moverley AR, McParland L, Brown S, Navarro-Coy $\mathrm{N}$, O’Dwyer JL, et al. Effect of tight control of inflammation in early psoriatic arthritis (TICOPA): a UK multicentre, open-label, randomised controlled trial. Lancet 2015;386:2489-98.

3. Smolen JS, Schols M, Braun J, Dougados M, FitzGerald O, Gladman DD, et al. Treating axial spondyloarthritis and peripheral spondyloarthritis, especially psoriatic arthritis, to target: 2017 update of recommendations by an international task force. Ann Rheum Dis 2018;77:3-17. 
4. Coates LC, FitzGerald O, Merola JF, Smolen J, van Mens LJJ, Bertheussen H, et al. Group for Research and Assessment of Psoriasis and Psoriatic Arthritis/Outcome Measures in Rheumatology consensus-based recommendations and research agenda for use of composite measures and treatment targets in psoriatic arthritis. Arthritis Rheumatol 2018;70:345-55.

5. Schoels MM, Braun J, Dougados M, Emery P, Fitzgerald O, Kavanaugh A, et al. Treating axial and peripheral spondyloarthritis, including psoriatic arthritis, to target: results of a systematic literature search to support an international treat-to-target recommendation in spondyloarthritis. Ann Rheum Dis 2014;73:238-42.

6. Kilic G, Kilic E, Nas K, Kamanli A, Tekeoglu I. Residual symptoms and disease burden among patients with psoriatic arthritis: is a new disease activity index required? Rheumatol Int 2019;39:73-81.

7. van Mens LJ, Turina MC, van de Sande MG, Nurmohamed MT, van Kuijk AW, Baeten DL. Residual disease activity in psoriatic arthritis: discordance between the rheumatologist's opinion and minimal disease activity measurement. Rheumatology 2018;57:283-90.

8. Rahman P, Zummer M, Bessette L, Baer P, Haraoui B, Chow A, et al. Real-world validation of the minimal disease activity index in psoriatic arthritis: an analysis from a prospective, observational, biological treatment registry. BMJ Open 2017;7:e016619.

9. Leung YY, Tam LS, Li EK. The perspective on psoriatic arthritis in Asia. Curr Rheumatol Rep 2011;13:369-75.

10. Leung YY, Fong W, Lui NL, Thumboo J. Effect of ethnicity on disease activity and physical function in psoriatic arthritis in a multiethnic Asian population. Clin Rheumatol 2017;36:125-31.

11. Chan A, Malhotra C, Do YK, Malhotra R, Ostbye T. Self reported pain severity among multiethnic older Singaporeans: does adjusting for reporting heterogeneity matter? Eur J Pain 2011;15:1094-9.

12. Lee YX, Kwan YH, Png WY, Lim KK, Tan CS, Lui NL, et al. Association of obesity with patient-reported outcomes in patients with axial spondyloarthritis: a cross-sectional study in an urban Asian population. Clin Rheumatol 2017;36:2365-70.

13. Hong C, Kwan YH, Leung YY, Lui NL, Fong W. Comparison of ankylosing spondylitis and non-radiographic axial spondyloarthritis in a multi-ethnic Asian population of Singapore. Int J Rheum Dis 2019;22:1506-11.

14. Rudwaleit M, van der Heijde D, Landewe R, Listing J, Akkoc N, Brandt J, et al. The development of Assessment of Spondyloarthritis international Society classification criteria for axial spondyloarthritis (part II): validation and final selection. Ann Rheum Dis 2009;68:777-83.

15. Taylor W, Gladman D, Helliwell P, Marchesoni A, Mease P, Mielants H; CASPAR Study Group. Classification criteria for psoriatic arthritis: development of new criteria from a large international study. Arthritis Rheum 2006;54:2665-73.

16. Healy PJ, Helliwell PS. Measuring clinical enthesitis in psoriatic arthritis: Assessment of existing measures and development of an instrument specific to psoriatic arthritis. Arthritis Rheum 2008;59:686-91.

17. Kwan YH, Tan JJ, Phang JK, Fong W, Lim KK, Koh HL, et al. Validity and reliability of the ankylosing spondylitis disease activity score with C-reactive protein (ASDAS-CRP) and bath ankylosing spondylitis disease activity index (BASDAI) in patients with axial spondyloarthritis (axSpA) in Singapore. Int J Rheum Dis 2019;22:2206-12.

18. Leung YY, Ho KW, Zhu TY, Tam LS, Kun EW, Li EK. Construct validity of the modified numeric rating scale of patient global assessment in psoriatic arthritis. J Rheumatol 2012;39:844-8.

19. Leung YY, Ho KW, Zhu TY, Tam LS, Kun EW, Li EK. Testing scaling assumptions, reliability and validity of medical outcomes study short-form 36 health survey in psoriatic arthritis. Rheumatology 2010;49:1495-501.
20. Leung YY, Tam LS, Kun EW, Ho KW, Li EK. Comparison of 4 functional indexes in psoriatic arthritis with axial or peripheral disease subgroups using Rasch analyses. J Rheumatol 2008; 35:1613-21.

21. Kwan YH, Fong WW, Lui NL, Yong ST, Cheung YB, Malhotra R, et al. Validity and reliability of the Short Form 36 health surveys (SF-36) among patients with spondyloarthritis in Singapore. Rheumatol Int 2016;36:1759-65.

22. Machado P, Landewe R, Lie E, Kvien TK, Braun J, Baker D, et al; Assessment of SpondyloArthritis international Society. Ankylosing Spondylitis Disease Activity Score (ASDAS): defining cut-off values for disease activity states and improvement scores. Ann Rheum Dis 2011;70:47-53.

23. Yahya F, Gaffney K, Hamilton L, Lonsdale E, Leeder J, Brooksby A, et al; BRITSpA. Tumour necrosis factor inhibitor survival and predictors of response in axial spondyloarthritis-findings from a United Kingdom cohort. Rheumatology 2018;57:619-24.

24. Sebastian A, Wojtala P, Lubinski L, Mimier M, Chlebicki A, Wiland P. Disease activity in axial spondyloarthritis after discontinuation of TNF inhibitors therapy. Reumatologia 2017;55:157-62.

25. Senabre Gallego JM, Rosas J, Marco-Mingot M, Garcia-Gomez JA, Santos-Soler G, Salas-Heredia E, et al; AIRE-MB Group. Clinical relevance of monitoring serum adalimumab levels in axial spondyloarthritis. Rheumatol Int 2019;39:841-9.

26. Coates LC, Fransen J, Helliwell PS. Defining minimal disease activity in psoriatic arthritis: a proposed objective target for treatment. Ann Rheum Dis 2010;69:48-53.

27. Schoels M, Aletaha D, Funovits J, Kavanaugh A, Baker D, Smolen JS. Application of the DAREA/DAPSA score for assessment of disease activity in psoriatic arthritis. Ann Rheum Dis 2010; 69:1441-7.

28. Schoels MM, Aletaha D, Alasti F, Smolen JS. Disease activity in psoriatic arthritis (PsA): defining remission and treatment success using the DAPSA score. Ann Rheum Dis 2016;75:811-8.

29. Dagfinrud H, Vollestad NK, Loge JH, Kvien TK, Mengshoel AM. Fatigue in patients with ankylosing spondylitis: a comparison with the general population and associations with clinical and self-reported measures. Arthritis Rheum 2005;53:5-11.

30. Thumboo J, Wu Y, Tai ES, Gandek B, Lee J, Ma S, et al. Reliability and validity of the English (Singapore) and Chinese (Singapore) versions of the Short-Form 36 version 2 in a multi-ethnic urban Asian population in Singapore. Qual Life Res 2013;22:2501-8.

31. Department of Statistics Singapore. Key indicators of the resident population. [Internet. Accessed February 22, 2021.] Available from: www.singstat.gov.sg/-/media/files/publications/cop2010/ census_2010_release1/indicators.pdf

32. Coates LC, Lubrano E, Perrotta FM, Emery P, Conaghan PG, Helliwell PS. What should be the primary target of "treat to target" in psoriatic arthritis? J Rheumatol 2019;46:38-42.

33. van Mens LJJ, van de Sande MGH, van Kuijk AWR, Baeten D, Coates LC. Ideal target for psoriatic arthritis? Comparison of remission and low disease activity states in a real-life cohort. Ann Rheum Dis 2018;77:251-7.

34. van Mens LJ, van de Sande MG, Fluri IA, Atiqi S, van Kuijk AW, Baeten DL. Residual disease activity and treatment adjustments in psoriatic arthritis in current clinical practice. Arthritis Res Ther 2017;19:226.

35. Marin J, Acosta Felquer ML, Ferreyra Garrot L, Ruta S, Rosa J, Soriano ER. Patients with psoriatic arthritis fulfilling the minimal disease activity criteria do not have swollen and tender joints, but have active skin. J Rheumatol 2016;43:907-10.

36. Wervers K, Vis M, Tchetveriko I, Gerards AH, Kok MR, Appels $\mathrm{CW}$, et al. Burden of psoriatic arthritis according to different definitions of disease activity: comparing minimal disease activity 
and the disease activity index for psoriatic arthritis. Arthritis Care Res 2018;70:1764-70.

37. Wang CT, Fong W, Kwan YH, Phang JK, Lui NL, Leung YY, et al. A cross-sectional study on factors associated with patient-physician discordance in global assessment of patients with axial spondyloarthritis: an Asian perspective. Int J Rheum Dis 2018;21:1436-42.

38. Wang CT, Kwan YH, Fong W, Xiong SQ, Leung YY. Factors associated with patient-physician discordance in a prospective cohort of patients with psoriatic arthritis: an Asian perspective. Int J Rheum Dis 2019;22:1209-15.

39. Tillett W, McHugh N, Orbai AM, Ogdie A, Leung YY, Coates LC, et al. Outcomes of the 2019 GRAPPA workshop on continuous composite indices for the assessment of psoriatic arthritis and membership-recommended next steps. J Rheumatol Suppl 2020;96:11-8.

40. Gorlier C, Orbai AM, Puyraimond-Zemmour D, Coates LC, Kiltz U, Leung YY, et al. Comparing patient-perceived and physician-perceived remission and low disease activity in psoriatic arthritis: an analysis of 410 patients from 14 countries. Ann Rheum Dis 2019;78:201-8.

41. Coates LC, Gottlieb AB, Merola JF, Boone C, Szumski A, Chhabra A. Comparison of different remission and low disease definitions in psoriatic arthritis and evaluation of their prognostic value. J Rheumatol 2019;46:160-5. 